\title{
A Avaliação da Consciência Sintática na Criança: uma Análise Metodológica ${ }^{1}$
}

\author{
Jane Correa ${ }^{2}$ \\ Universidade Federal do Rio de Janeiro
}

\begin{abstract}
RESUMO - Desde a década de 1970, observa-se o interesse crescente na investigação do desenvolvimento das habilidades metalingüísticas na criança, bem como pelo papel de tais habilidades na aquisição da leitura e na escrita. Dentre tais habilidades, destaca-se a consciência sintática. O presente trabalho objetiva realizar uma revisão metodológica da literatura a respeito da consciência sintática de forma a descrever as tarefas utilizadas para sua mensuração, bem como discutir a validade e propriedade de tais instrumentos na investigação do desenvolvimento das habilidades metassintáticas na criança. Na presente análise, discute-se a eficácia das tarefas clássicas de consciência sintática (tarefas de julgamento, correção, repetição e localização) e tarefas de uso recente na literatura (tarefas de analogias sintáticas e de replicação) para efetivamente acessar a manipulação intencional do conhecimento sintático pela criança.
\end{abstract}

Palavras-chave: consciência sintática; desenvolvimento metalingüístico; tarefas de consciência sintática.

\section{The Evaluation of Children's Syntactic Awareness: a Methodological Analysis}

\begin{abstract}
Since the 1970s, there is an increasing interest in the investigation of children's metalinguistic development and the role played by metalinguistic abilities to reading and writing. Among such abilities, one can name the syntactic awareness. The present study aims to carry out a methodological literature review on syntactic awareness in order to describe the tasks used to measure it and to discuss the validity and the appropriateness of such instruments to the research on the development of metasyntactic abilities in children. In the present analysis, we discuss the efficacy of the classical syntactic awareness tasks (judgment, correction, repetition and localization) as well as tasks of recent use in literature (analogy and replication tasks) in effectively access children's intentional manipulation of their syntactic knowledge.
\end{abstract}

Key words: syntactic awareness; metalinguistic development; syntactic awareness tasks.

O emprego do termo "meta" para designar o conhecimento e controle intencional por parte do indivíduo de sua própria atividade cognitiva se estabelece na literatura psicológica na década de 70 (Bialystok, 1993). O termo "metacognição" refere-se ao conhecimento que o indivíduo tem sobre seus processos cognitivos e produtos (Flavell, 1976) ou, definido de maneira mais concisa, diz respeito à cognição sobre a cognição (Flavell, Miller \& Miller,1993). Várias habilidades poderiam ser ditas como metacognitivas, dentre elas a metalinguagem (Gombert, 1993). Por ser caracterizada a partir de seu objeto (a linguagem), a metalinguagem diferencia-se das outras habilidades metacognitivas (por exemplo, a metamemória, a meta-atenção e a meta-aprendizagem) à medida que estas são definidas pela função cognitiva a que se referem.

A definição da metalinguagem no âmbito da Psicologia Cognitiva compreende um duplo aspecto, dualidade esta presente também nas definições das habilidades metacognitivas de maneira geral (Brown, Bransford, Ferrara \& Campione, 1983): a cognição de suas formas e a regulação de suas atividades. De forma mais específica, em relação à metalinguagem: a cognição sobre a linguagem e a auto-regulação

1 Agradecimentos ao CNPq e FAPERJ pelo apoio concedido.

2 Endereço: Universidade Federal do Rio de Janeiro, Instituto de Psicologia, Avenida Pasteur, 250, Praia Vermelha, Rio de Janeiro, RJ, Brasil 22290-240. E-mail: janecorrea@ rjnet.com.br das atividades psicolingüísticas. Existem dois pontos de convergência nas definições de metalinguagem encontradas na literatura psicológica (Garton \& Pratt, 1990; Gombert, 1991): a) a reflexão sobre a linguagem, considerada como objeto independente do significado que veicula e b) manipulação intencional das estruturas lingüísticas.

A metalinguagem é considerada um construto multidimensional, envolvendo diversas competências. As primeiras, e mais tradicionais, classificações das habilidades metalingüísticas incluem (Bialystok, 1993): a consciência fonológica (reflexão sobre a estrutura fonológica da língua), a consciência da palavra (compreensão da natureza da palavra como unidade), a consciência sintática (reflexão sobre a estrutura sintática da língua) e a consciência pragmática (entendimento dos usos sociais da linguagem). Alterações introduzidas recentemente têm sido mais no sentido da designação de outras habilidades metalingüísticas, como por exemplo, a consciência morfológica (Carlisle, 2000; Levin, Ravid \& Rapaport, 1999; Mahony, Singson \& Mann, 2000) e a consciência textual (Gombert, 1992), do que na proposição de modificação da natureza do conceito. A consciência morfológica diz respeito à reflexão sobre a estrutura morfológica da língua enquanto a consciência textual refere-se ao conhecimento e controle intencional da compreensão e da produção de texto. Gombert (1992) relaciona, ainda, o termo consciência semântica para designar os aspectos semânticos da linguagem, 
incluindo também o que anteriormente se designava como consciência da palavra. A emergência e o desenvolvimento das habilidades metalingüísticas ocorrem à medida que as crianças se tornam mais sensíveis às propriedades estruturais da linguagem. Este desenvolvimento não é, contudo, linear e nem ocorre de maneira similar para as diversas habilidades acima relacionadas. O desenvolvimento das habilidades metalingüísticas vai depender do nível de representação requerido em cada habilidade, bem como pelo grau de atenção e controle envolvidos nas diversas atividades.

Investigações na área têm voltado sua atenção para a mensuração e descrição do desenvolvimento das diferentes habilidades metalingüísticas, como também para sua influência no aprendizado da leitura e da escrita. A este respeito, já há uma vasta literatura não só sobre as diversas habilidades que compõem a consciência fonológica (Gough, Larson \& Yopp, 1995; Yopp,1988), como também acerca de sua importância para a alfabetização em diversas línguas alfabéticas (Bradley \& Bryant,1983; Capovilla \& Capovilla, 2000; Caravolas,1993; Cardoso-Martins, 1991,1995ab; Correa, Spinillo \& Leitão, 2001; Goswami \& Bryant, 1990; Lundberg, Frost, \& Petersen, 1988; Rego, 1995). Entre a consciência fonológica e a alfabetização existe uma relação de causalidade recíproca: um certo grau de consciência fonológica é necessário à alfabetização, assim como, o fato de se aprender a ler e a escrever uma língua alfabética contribui para o desenvolvimento ulterior de competências mais complexas de análise fonológica (Goswami \& Bryant, 1990; Morais, 1987; Wagner \& Torgesen, 1987).

O domínio das correspondências grafofônicas não é, por sua vez, suficiente para a escrita de acordo com a norma ortográfica. Para escrever ortograficamente, as crianças precisam desenvolver, por exemplo, competências que permitam refletir sobre a estrutura das palavras e sua colocação na frase. Neste sentido, crianças que desenvolvessem maior sensibilidade à organização sintática da língua teriam melhor desempenho em tarefas de leitura (Tunmer, Nesdale \& Wright, 1987) e escrita (Rego \& Bryant,1993; Rego \& Buarque, 1997). No entanto, não existe ainda um volume tão extenso de pesquisas para a consciência sintática como aquele gerado para a consciência fonológica no que concerne às dimensões envolvidas, às tarefas que possam melhor mensurá-la, à descrição de seu desenvolvimento ou ao detalhamento de sua relação com o aprendizado da leitura e da escrita.

Neste sentido, o presente trabalho objetiva realizar uma revisão da literatura a respeito da consciência sintática de forma a descrever as tarefas utilizadas para sua mensuração, bem como discutir sua validade e propriedade na investigação do desenvolvimento das habilidades metassintáticas na criança.

\section{Consciência Sintática: Definição e Mensuração}

A consciência sintática pode ser definida como a capacidade para refletir sobre os aspectos sintáticos da língua e para controlar deliberadamente sua aplicação (Gombert, 1992). Correções espontâneas da fala foram tomadas como as primeiras evidências empíricas da presença de habilidades metassintáticas na criança. Foi observado que crianças de 2 a 3 anos de idade já se mostram capazes de corrigir seus enunciados (Gombert, 1992). No entanto, tais correções estão relacionadas mais à intenção da criança para se comunicar e monitorar o sentido daquilo que fala do que propriamente para focalizar sua atenção nos aspectos formais das frases que produz.

Um grande desafio à pesquisa sobre a origem e desenvolvimento da consciência sintática é, portanto, o da sua mensuração, ou seja, o da avaliação do acesso à reflexão intencional sobre a sintaxe. Algumas tarefas podem ser consideradas como clássicas na investigação acerca da origem e do desenvolvimento da consciência sintática. São elas: tarefa de julgamento ou de aceitabilidade, tarefa de correção, tarefa de repetição, tarefa de localização e tarefa de produção.

\section{Tarefa de julgamento de frases}

Consiste na apresentação oral de uma lista contendo frases bem estruturadas e sentenças inaceitáveis gramaticalmente para que a criança julgue a sua aceitabilidade sintática (de Villiers \& de Villiers, 1972, 1974; Gleitman, Gleitman \& Shipley, 1972; Scholl \& Ryan, 1975; Smith \& TargerFlusberg, 1982). As incorreções ficam por conta de frases cujos termos foram invertidos ou emprego inapropriado ou ausência de certos morfemas em determinados vocábulos. De início, à tarefa de julgamento, seguia-se a solicitação para que as crianças corrigissem as frases julgadas incorretas. Uma dificuldade bastante comum relacionada ao emprego da tarefa de aceitabilidade com crianças, principalmente as mais novas, diz respeito às diferentes exigências que se seguem ao julgamento das frases. Quando a frase é julgada correta, pede-se à criança que proceda ao julgamento da frase seguinte. Caso a frase esteja incorreta, pede-se a correção da frase. Algumas crianças podem demonstrar dificuldade e/ou falta de interesse em dar explicações sobre suas respostas pelo simples fato de terem que corrigi-la em seguida. Desta forma, as competências metalingüísticas das crianças, principalmente as mais novas, poderiam estar sendo subestimadas.

Uma possível solução para o problema apontado acima seria o de se pedir apenas o julgamento da aceitabilidade das frases sem a necessidade de correção daquelas consideradas inaceitáveis, dissociando-se, assim, as tarefas de julgamento e de correção de frases (Bohannon, 1976; Rego, 1993). Como o julgamento de aceitabilidade das frases é influenciado pela complexidade das frases usadas, frases mais longas e, portanto, mais complexas fazem com que o desempenho na tarefa possa variar não apenas em relação às capacidades metassintáticas das crianças, mas também em relação a outras funções cognitivas como, por exemplo, à memória de trabalho. Desta forma, o aumento da complexidade das frases afetaria principalmente o desempenho das crianças mais novas, que são também aquelas com níveis menores de capacidade de memória de trabalho.

Por outro lado, o emprego de frases mais simples não torna menos controversos os resultados obtidos na tarefa. Ao contrário, o uso de sentenças menos complexas em tarefas de julgamento, onde a correção não fosse solicitada, não permite que se atribua o sucesso da criança ao uso de critérios puramente sintáticos, uma vez que violações de natureza sintática acarretam também violações de ordem semântica. As crianças 
poderiam estar baseando seu julgamento em critérios puramente semânticos, a partir do entendimento que pudessem ter do significado das sentenças apresentadas. Assim sendo, poderíamos, desta vez, superestimar o desempenho das crianças mais novas, concluindo pela emergência de habilidades metassintáticas mais cedo do que na verdade ocorreriam. De mais a mais, independentemente da complexidade das frases empregadas, a criança pode ser bem sucedida na tarefa de julgamento de aceitabilidade de frases simplesmente porque toma sua decisão baseada na detecção da dissonância global dos enunciados, sem que haja de fato a detecção explícita da agramaticalidade presente nas frases.

De forma contrária, a criança pré-escolar e nos primeiros anos escolares poderia aceitar como corretos itens em que haja a ausência de um morfema marcador (como por exemplo, os marcadores de plural) não por ausência de habilidades metassintáticas, mas por tomar como modelo o dialeto falado em casa. Uma forma de avaliar a consciência sintática, sem o inconveniente da diferença no tipo de exigência imposta à criança na tarefa de julgamento, é a de, novamente, se dissociar julgamento e correção de frases.

\section{Tarefa de correção}

Desta feita, as crianças não deveriam fazer qualquer julgamento sobre a aceitabilidade das sentenças já que seriam apresentadas somente a frases consideradas inaceitáveis gramaticalmente (Guimarães, 2003; Leal \& Roazzi, 1999; Pratt, Tunmer \& Bowey, 1984; Rego, 1993, 1997; Rego \& Bryant, 1993; Rego \& Buarque, 1997; Tunmer \& cols., 1987). Tais frases seriam, geralmente, atribuídas a uma marionete que falaria “errado". Seria pedido, então, à criança a correção de cada uma das frases. Geralmente, a tarefa de correção sintática envolve, para algumas frases, itens relativos à reordenação de seus termos integrantes (por exemplo: de, copo, quebrou, água, um, João) e, para outras, corrigir o uso inapropriado ou mesmo a ausência de um morfema.

O emprego da tarefa de correção, por si só, não permite ainda estabelecer com clareza o desenvolvimento da consciência sintática, especialmente em crianças mais novas. De forma similar à tarefa de julgamento, nos itens referentes a ausência de marcador, a preferência dialetal pode influenciar a resposta da criança. Neste caso, a tarefa poderia parecer sem sentido à criança por demandar a correção de sentenças que para ela seriam perfeitamente aceitáveis segundo o dialeto falado em sua casa.

A tarefa de correção deixa dúvidas quanto à possibilidade de acesso efetivo ao conhecimento metassintático da criança. Isto porque se observa uma tendência natural da criança, mesmo as mais novas, à normalização das frases (Byalistok \& Ryan, 1985). Desta forma, as correções poderiam ser realizadas sem que a criança estivesse, de fato, refletindo sobre a natureza do erro. Consequientemente, as correções poderiam ser mais a expressão de um conhecimento tácito sobre a sintaxe da língua do que da aplicação de habilidades de natureza metassintática. Por outro lado, as crianças poderiam também proceder à solução da tarefa de correção utilizando critérios puramente semânticos, e neste caso, não necessitariam recorrer a seus conhecimentos sintáticos.

\section{Tarefa de repetição}

Como forma de poder determinar a emergência do emprego efetivo das habilidades metassintáticas pelas crianças, alguns pesquisadores passaram a fazer uso, juntamente com as tarefas de julgamento e correção, da tarefa de repetição (Bowey, 1986; Gaux \& Gombert, 1999a; Ryan \& Ledger, 1979). Essa tarefa consiste em se pedir à criança que repita a sentença ouvida sem qualquer alteração. Dada a tendência natural de se normalizar sentenças inadequadas, a repetição de sentenças inaceitáveis poderia exigir da criança o controle intencional de sua atividade. Desta forma, o uso da tarefa de repetição permitiria, em princípio, estabelecer a possibilidade, principalmente para o caso das crianças mais novas, do uso de habilidades metassintáticas no julgamento e correção de sentenças. Índices muito baixos de desempenho na tarefa de repetição, acompanhados de elevado percentual de sucesso nas tarefas de julgamento e correção de frases, indicariam que o bom desempenho da criança nestas últimas tarefas resultaria de um conhecimento tácito da língua e não de uma reflexão intencional.

No entanto, tarefas de repetição não são, ainda, por si só, uma medida efetiva de consciência sintática visto que não permitiriam, sem qualquer sombra de dúvida, o exame do uso intencional do conhecimento sintático pela criança. É possível que as crianças repitam as frases que tenham podido entender melhor, ou aquelas cujos vocábulos lhes são familiares.

\section{Tarefas de localização}

Na tentativa de se verificar se as correções realizadas pelas crianças decorrem do uso de habilidades metalingüísticas, foram empregadas, ainda, tarefas nas quais as crianças eram solicitadas a apontar o erro nas frases apresentadas, explicando, em seguida, a razão pela qual o enunciado estaria incorreto (Smith-Lock \& Rubin,1993; Gaux \& Gombert, 1999a).

Os resultados advindos da aplicação destas tarefas também não podem ser tomados como conclusivos em relação à emergência da consciência sintática na criança. Não é possível determinar no caso da localização (não seguida de explicação), se o desempenho da criança se deva ao uso de habilidades metalingüísticas já que, conforme discutido anteriormente, violações sintáticas acarretam em maior ou menor grau violações de natureza semântica, o que implicaria, por si só, o estranhamento do enunciado. Por sua vez, o pedido de explicação para que a criança determinasse a natureza do erro, não estaria também isento de ressalvas. A ausência de verbalização de uma regra gramatical não implica a incapacidade de sua utilização por parte da criança (Green \& Hecht, 1992; Sorace, 1985). Pedindo-se à criança a justificativa ou explicação para suas respostas, poderíamos estar maximizando as chances de obtermos falsos negativos, ou seja, poderíamos estar avaliando erroneamente crianças que, apesar de fazerem uso de habilidades metalingüísticas para julgamento das sentenças, teriam dificuldade em expressar verbalmente o emprego que fizeram de tais habilidades.

Recorrendo-se à definição de consciência sintática constata-se a referência à manipulação intencional do conhecimento gramatical, o que não implica necessariamente sua expressão 
verbal. Desta feita, a enunciação verbal não pode, por definição, ser tomada como medida de habilidade metassintática. É possível, conceitualmente, que a criança possa estar manipulando intencionalmente o conhecimento sintático que possua e encontre, ao mesmo tempo, dificuldade em comunicar através de palavras a operação mental realizada. É importante observar, ainda, que a verbalização da natureza do erro seria favorecida pelo conhecimento do vocabulário gramatical adequado, o que dependeria em última instância também do nível de escolaridade da criança.

Por outro lado, saber enunciar uma regra gramatical também não é garantia da existência de habilidades metalingüísticas. Muitas vezes, por influência do tipo de ensino recebido, tais regras são memorizadas sem que a criança se dê conta de seu sentido. Assim sendo, existe, por um lado, um hiato entre a capacidade de usar intencionalmente os conhecimentos lingüísticos e a capacidade de enunciá-los e por outro, a evidência de que a recitação de uma regra gramatical não decorre necessariamente da manipulação intencional dos conhecimentos lingüísticos.

\section{Tarefa de completamento ou produção}

Tentativas de mensuração da consciência sintática têm sido feitas também através do emprego da tarefa de completamento ou de produção. Nesta tarefa, a criança deve enunciar as palavras que faltam em uma frase ou história, ou ainda, completar o morfema final de uma palavra incompleta inserida em uma frase (Leal \& Roazzi, 1999; Nunes, Bryant \& Bindman, 1997ab; Rego \& Bryant, 1993; Tunmer \& cols., 1987).

A tarefa de completamento, assim como as demais, não possibilita determinar o uso de habilidades metassintáticas dissociadas dos aspectos semânticos. No caso da tarefa de completamento, mesmo quando são usadas pseudopalavras, a criança tem o contexto para ajudá-la na escolha da palavra apropriada. Não é possível, portanto, determinar se o desempenho da criança não ocorreu apenas pelo uso dos conhecimentos tácitos que possui da língua (Gaux \& Gombert, 1999b). Desta forma, não é possível concluir de maneira inequívoca se o desempenho decorreu do uso intencional e da manipulação deliberada das regras gramaticais.

\section{Tarefa de analogia sintática}

As tentativas de avaliação da consciência sintática realizadas nas pesquisas desenvolvidas a partir dos anos 90 deram origem a duas novas tarefas: tarefa de analogia sintática e tarefa de replicação. A tarefa de analogia sintática (Nunes \& cols., 1997a) é estruturada segundo o esquema: A está para B assim como C está para D. A e B são duas sentenças, por exemplo, uma frase com o verbo no presente (Maria come biscoito) e outra no passado (Maria comeu biscoito); Cé uma outra frase com a mesma estrutura sintática da frase A, em nosso exemplo, uma sentença no presente (Ricardo faz um desenho) e D, frase a ser produzida pela criança, operando a transformação observada de A para B. No exemplo, a criança deverá dizer a frase $\mathrm{C}$ com o verbo no passado (Ricardo fez um desenho). No caso de nosso exemplo, a intenção seria a de que a criança pudesse mostrar o reconhecimento e produção da relação presente e passado dos verbos, sejam os verbos regulares ou irregulares.

A tarefa de analogia sintática impõe, portanto, à criança a detecção da relação gramatical entre o primeiro par de itens da tarefa e a sua aplicação intencional ao segundo par. Contudo, a tarefa não está isenta de restrições. Como a própria designação da tarefa já anuncia, a tarefa depende da capacidade da criança em fazer uso do raciocínio por analogia. Não estamos assim medindo apenas a competência metalingüística da criança, mas a habilidade da criança em usar seu conhecimento metassintático associado a outra operação de pensamento, ou seja, a sua capacidade de raciocinar por analogia. Desta forma, só estaríamos conseguindo avaliar as habilidades metassintáticas daqueles que também possuíssem habilidades de fazer uso de analogias. A capacidade de usar analogias é, por sua vez, expressão da emergência do raciocínio proporcional, ou seja, depende em última instância da emergência e do desenvolvimento do pensamento multiplicativo na criança.

\section{Tarefa de replicação}

A tarefa de replicação, descrita por Gaux e Gombert (1999a), consiste em se pedir à criança que reproduza, em duas sentenças corretas, o mesmo erro gramatical localizado e corrigido em uma frase anteriormente apresentada. Por exemplo, na frase "O menina é guloso", após localizar e corrigir o erro, a criança deverá reproduzi-lo em duas outras frases: no caso, "A bicicleta é nova" e "O rapaz anda nervoso".

Pretende-se, nesta tarefa, que a criança possa detectar violações de natureza sintática e fazer uso consciente de seu conhecimento sintático pela reprodução intencional do erro identificado sem que haja necessidade de se recorrer à explicação verbal de suas respostas. A tarefa de replicação, entretanto, parece requerer sobremaneira da memória de trabalho, principalmente se apresentada apenas oralmente, ou seja, sem a apresentação escrita das frases. Neste sentido, a eficácia da tarefa estaria associada ao nível de memória da criança, se apresentada oralmente ou, se apresentada em forma escrita, à habilidade de leitura da criança.

Gaux e Gombert (1999b) observam que a eficácia da tarefa de replicação em acessar a manipulação intencional do conhecimento sintático pela criança pode ser comprometida segundo o tipo de item construído para a tarefa. As crianças tendem a reproduzir mais facilmente o erro na frase correta uma vez que haja semelhança fonológica do item a transformar com o da frase-modelo. Por exemplo, o erro que aparece em "O vendedora está cansado" será mais facilmente reproduzido na frase "O diretor chora emocionado" do que na sentença "O rapaz anda ligeiro". Da mesma forma, a semelhança entre a posição do erro na frase-modelo e nas frases onde este deva ser replicado, principalmente quando o item envolver a inversão da ordem da palavra ou de sintagmas, constitui indício a partir do qual a criança pode também obter mais facilmente sucesso na tarefa.

Itens construídos para a tarefa de replicação que incluam semelhanças fonológicas e de posição entre os vocábulos nas frases permitem que o sucesso da criança possa ser resultado do conhecimento tácito que ela tenha da sintaxe ao invés do uso de suas habilidades metassintáticas. As ressalvas feitas 
anteriormente em relação à construção de itens para a tarefa de replicação também são válidas quando da construção da tarefa de analogia sintática.

\section{Considerações Finais}

Não resta dúvida de que, ao longo do desenvolvimento, ocorre uma mudança significativa na maneira como conceitualizamos e fazemos uso da linguagem. Antes utilizada como instrumento de comunicação social, permitindo à criança se expressar e interagir socialmente, a linguagem torna-se, ao longo do desenvolvimento, por força da escolarização, quando do aprendizado da língua escrita, objeto de conhecimento.

Tomar a língua como objeto de conhecimento imporá à criança novas demandas. O constante apelo a que se tome a linguagem como objeto do aprender requererá o uso em maior ou menor grau de habilidades metalingüísticas. Existe hoje uma vasta literatura a respeito do papel desempenhado pela consciência fonológica para a aquisição da língua escrita (Cardoso-Martins, 1995b). Observa-se que embora a consciência fonológica seja importante no domínio do princípio alfabético pela criança, este não é suficiente para predizer o desenvolvimento ulterior da leitura e da escrita.

Desta feita, o interesse pelo estudo da consciência sintática adquire importância não só pela contribuição que possa fornecer para a elaboração de um modelo mais geral do desenvolvimento de habilidades metalingüísticas na criança, como também, pelo papel que possa desempenhar como preditora do sucesso no aprendizado da leitura e da escrita (Rego, 1995; 1997; Rego \& Buarque, 1997).

Assim sendo, a pesquisa sobre o desenvolvimento das habilidades metassintáticas na criança não pode avançar sem que atenção especial seja dada a maneira pela qual medimos tais habilidades. O primeiro desafio que se impõe, portanto, às pesquisas na área é poder assegurar-se que através das tarefas empregadas estejamos efetivamente acessando a manipulação intencional do conhecimento sintático da criança, conforme requer a própria definição de consciência sintática.

A análise das tarefas consideradas clássicas no exame da consciência sintática - tarefas de julgamento, correção, repetição e localização - nos mostra que tais tarefas falham em distinguir, através do desempenho da criança, o que seria produto do processamento lingüístico ordinário e o que seria derivado da atividade metassintática da criança. Dada a natureza destas tarefas, a criança poderia obter sucesso em sua atividade valendo-se apenas do conhecimento tácito que possui da língua. Tal observação é válida, mesmo quando são elaborados para estas tarefas itens que incluem o uso de pseudopalavras ou palavras inventadas.

Avanços em relação à construção de tarefas que possam avaliar a intencionalidade na manipulação do conhecimento sintático pela criança foram dados pelo emprego das tarefas de analogias sintáticas e de replicação. O emprego de tais tarefas, no entanto, não está a salvo de ressalva uma vez que avaliam o emprego de habilidades metassintáticas com exigência de outros processos cognitivos, implicando operações mais sofisticadas de pensamento. Isto poderia, na verdade, elevar a idade segundo a qual poderíamos falar da emergência de habilidades metassintáticas na criança. Cuidado especial deve ser dado, ainda, à construção dos itens nestas tarefas, uma vez que similaridades fonológicas e de posição permitem o emprego de conhecimentos tácitos da sintaxe da língua para a resolução da tarefa.

É importante sublinhar que as tarefas que avaliam a consciência sintática deveriam a rigor ser entendidas como sintático-semântica porque é impossível tratar a sintaxe de maneira independente da semântica (Gombert, 1992). Isto tem implicações na construção de tarefas para o exame da consciência sintática. Desta forma, o importante na avaliação da consciência sintática não é almejar tratar a sintaxe sem qualquer interferência da semântica, já que não é possível haver manipulação intencional daquilo cujo significado não compreendemos. A verdadeira natureza da tarefa de consciência sintática está em se ocupar do acesso à manipulação intencional do conhecimento sintático pela criança em um dado contexto, ou seja, distinguindo o processamento lingüístico ordinário da sintaxe da atividade metassintática.

As tarefas clássicas de investigação da consciência sintática parecem, por sua natureza, mais relacionadas ao processamento lingüístico habitual do que à manipulação intencional da sintaxe da língua. No entanto, se por um lado, os resultados de investigações usando as tarefas consideradas clássicas na avaliação da consciência metassintática apresentam problemas em seu emprego isolado, por outro, tomados em conjunto nos permitem delinear alguns aspectos referentes à conceitualização da sintaxe pela criança que fossem precursores do desenvolvimento da consciência sintática.

Aos desafios impostos à avaliação da consciência sintática que foram examinados ao longo deste trabalho, somam-se outros advindos da construção de um modelo cognitivo geral para o desenvolvimento da metalinguagem pela criança. Alguns pesquisadores (Nunes \& cols., 1997ab; Sá,1999) discutem, por exemplo, que do ponto de vista do funcionamento psicológico, a conceitualização feita pela criança acerca dos aspectos morfológicos não é independente daquela sobre os aspectos sintáticos da língua. Nunes e colaboradores (1997b) propõem o termo mais geral de "consciência gramatical" de forma a compreender tanto a consciência morfológica quanto a consciência sintática. Conforme observa Sá (1999), o termo "consciência gramatical" não seria o mais apropriado para expressar a interdependência entre a conceitualização da sintaxe e da morfologia pela criança. O uso do termo "gramatical" poderia compreender outros aspectos da gramática, entre eles, a fonologia. Por seu turno, a Lingüística (Crystal, 1991; Richard, Platt \& Platt,1992) reconhece na morfossintaxe o estudo dos fatos morfológicos da língua derivados das relações estabelecidas no enunciado (sintaxe), bem como dos aspectos sintáticos a partir de suas implicações morfológicas (Michaelis, 1998). Sublinha-se, desta maneira, a interação e a interdependência entre sintaxe e morfologia.

Para lidar com as questões relativas à validade das tarefas empregadas, futuras pesquisas na área deverão debruçarse mais sobre a própria definição de consciência sintática, discutindo a relação entre a conceitualização da sintaxe e da morfologia pela criança. $\mathrm{O}$ que temos hoje em relação à avaliação da consciência sintática é limitado pela conceitualização que possuímos desta habilidade metalingüística. Somente o trabalho de natureza conceitual, com o aprimoramento das definições que já possuímos, poderá propiciar o engendramento 
de tarefas apropriadas para a compreensão das habilidades metalingüísticas da criança. Somente sabendo o que queremos medir é que podemos construir instrumentos que de fato nos permitam medir o que supostamente deveriam medir.

\section{Referências}

Bialystok, E. (1993). Metalinguistic awareness: The development of children's representations of language. Em C. Pratt \& A.F. Garton (Orgs.), Systems of representation in children: Development and use (pp. 211-233). New York: Wiley.

Bialystok, E. \& Ryan, E.B. (1985). Toward a definition of metalinguistic skill. Merrill-Palmer Quarterly, 31(3), 229-251.

Bohannon, J.N. (1976). Normal and scrambled grammar in discrimination, imitation and comprehension. Child Development, 47(3), 669-681.

Bowey, J. (1986). Syntactic awareness and verbal performance from preschool to fifth grade. Journal of Psycholinguistic Research, 15(4), 285-308.

Bradley, L. \& Bryant, P. (1983). Categorising sounds and learning to read - a causal connection. Nature, 301, 419-521.

Brown, A., Bransford, J., Ferrara, R. \& Campione, J. (1983). Learning, remembering, and understanding. Em P. Mussen, J.H. Flavell \& E. Markman (Orgs.), Handbook of child psychology, vol 3: cognitive development (pp. 77-166). New York: Wiley.

Capovilla, A.G.S. \& Capovilla, F.C. (2000). Efeitos do treino de consciência fonológica em crianças com baixo nível sócioeconômico. Psicologia: Reflexão e Crítica, 13(1), 7-24.

Caravolas, M. (1993). Language-specific influences of phonology and orthography on emergent literacy. Em J. Altarriba (Org.), Cognition and culture: A cross-cultural approach to cognitive psychology (pp. 177-205). North-Holland: Elsevier Science Publishers.

Cardoso-Martins, C. (1991). Awareness of phonemes and alphabetic literacy acquisition. British Journal of Educational Psychology, 61(2), 164-173.

Cardoso-Martins, C. (Org.) (1995a). Consciência fonológica e alfabetização. Petrópolis: Vozes.

Cardoso-Martins, C. (1995b). Sensitivity to rhymes, syllables and phonemes in literacy acquisition in Portuguese. Reading Research Quarterly, 30(4), 808-828.

Carlisle, J.F. (2000). Awareness of the structure and meaning of morphologically complex words: impact on reading. Reading and Writing: An Interdisciplinary Journal, 12(3-4), 169-190.

Correa, J., Spinillo, A. \& Leitão, S. (2001). Desenvolvimento da linguagem: Escrita e textualidade. Rio de Janeiro: FAPERJ/ Nau.

Crystal, D. (1991). A dictionary of linguistics and phonetics. Oxford: Blackwell.

de Villiers, P.A. \& de Villiers, J.G. (1972). Early judgements of semantic and syntactic acceptability by children. Journal of Psycholinguistic Research, 1(4), 299-310.

de Villiers, J.G. \& de Villiers, P.A. (1974). Competence and performance in child language: Are children really competent to judge? Journal of Child Language, 1(1), 11-22.

Flavell, J.H. (1976). Metacognitive aspects of problem solving. Em L.B. Resnick (Org.), The nature of intelligence. Hillsdale: Lawrence Erlbaum.

Flavell, J.H., Miller, P.H. \& Miller, S. (1993). Cognitive development ( $3^{\text {a }}$ ed.). New Jersey: Prentice-Hall.
Garton,A. \& Pratt, C. (1990). Learning to be literate: The development of spoken \& written language. Oxford: Blackwell.

Gaux, C. \& Gombert, J. E. (1999a). Implicit and explicit syntactic knowledge and reading in pre-adolescents. British Journal of Developmental Psychology, 17(2), 169-188.

Gaux, C. \& Gombert, J.E. (1999b). La conscience syntaxique chez les préadolescents: Question de méthodes. L'Année Psychologique, 99(1), 45-74.

Gleitman, L.R., Gleitman, H. \& Shipley, E.F. (1972). The emergence of the child as grammarian. Cognition, 1(2-3), 137-164.

Gombert, J. (1991). Les activités métalinguistiques comme objet d'étude de la psycholinguistique cognitive. Bulletin de Psychologie, XLIV(399), 92-99.

Gombert, J. (1992). Metalinguistic development. London: HarvesterWheatsheaf.

Gombert, J. (1993). Metacognition, metalanguage and metapragmatics. International Journal of Psychology, 28(5), 571-580.

Goswami, U. \& Bryant, P. (1990). Phonological skills and learning to read. London: Erlbaum.

Gough, P.B., Larson, K. \& Yopp, H. (1995). A estrutura da consciência fonológica. Em C. Cardoso-Martins, C. (Org.), Consciência fonológica e alfabetização (pp. 13-35). Petrópolis: Vozes.

Green, P.S. \& Hecht, K. (1992). Implicit and explicit grammar: An empirical study. Applied Linguistics, 13(2), 168-184.

Guimarães, S.R.K. (2003). Dificuldades no desenvolvimento da lectoescrita: O papel das habilidades metalingüísticas. Psicologia: Teoria e Pesquisa, 19(1), 33-45.

Leal, T.F. \& Roazzi, A. (1999). Uso de pistas lingüísticas na leitura: Análise do efeito da consciência sintático-semântica sobre a compreensão de textos. Revista Portuguesa de Educação, 12(2), 77-104.

Levin, I., Ravid, D. \& Rapaport, S. (1999). Developing morphological awareness and learning to write: A two-way street. Em T. Nunes (Org.), Learning to read: An integrated view from research and practice. Dordrecht: Kluwer.

Lundberg, I., Frost, J. \& Petersen, O.-P. (1988). Effects of a extensive program for stimulating phonological awareness in preschool children. Reading Research Quartely, 23(3), 263-284.

Mahony, D., Singson, M. \& Mann,V. (2000). Reading ability and sensitivity to morphological relations. Reading and Writing: An Interdisciplinary Journal, 12(3-4), 191-218.

Michaelis (1998). Moderno dicionário da língua portuguesa. São Paulo: Melhoramentos.

Morais, J. (1987). Phonetic awareness and reading acquisition. Psychological Research, 49(2-3), 147-152.

Nunes, T., Bryant, P. \& Bindman, M. (1997a). Learning to spell regular and irregular verbs. Reading and Writting: An Interdisciplinary Journal, 9(5-6), 427-449.

Nunes, T.; Bryant, P. \& Bindman, M. (1997b). Morphological spelling strategies: Developmental stages and processes. Developmental Psychology, 33(4), 637-649.

Pratt, C., Tunmer, W.E. \& Bowey, J. (1984). Children's capacity to correct grammatical violations in sentences. Journal of Child Language, 11(1), 129-141.

Rego, L.L.B. (1993). O papel da consciência sintática na aquisição da língua escrita. Temas em Psicologia, 1(1), 79-111.

Rego, L.L.B. (1995). Diferenças individuais na aprendizagem inicial da leitura: Papel desempenhado por fatores metalingüísticos. Psicologia: Teoria e Pesquisa, 11(1), 51-60. 
Rego, L.L.B. (1997). The connection between syntactic awareness and reading: Evidence from Portuguese-speaking children taught by a phonic method. International Journal of Behavioral Development, 20(2), 349-365.

Rego, L.L.B. \& Buarque, L.L. (1997). Consciência sintática, consciência fonológica e aquisição de regras ortográficas. Psicologia: Reflexão e Crítica, 10(2), 199-217.

Rego, L.L.B. \& Bryant, P. (1993). The connection between phonological, syntactic and semantic skills and children's and spelling. European Journal of Psychology of Education, 8(3), 235-246.

Richard, J.C. Platt, J. \& Platt, H. (1992). Dictionary of language teaching \& applied linguistics. Essex: Longman.

Ryan, E.B. \& Ledger, G.W. (1979). Grammaticality judgments, sentences repetitions, and sentence corrections of children learning to read. International Journal of Psycholinguistics, 6(4),23-40.

Sá, J.L.N.S. (1999). A relação entre a consciência morfossintática e a escrita ortográfica. Dissertação de Mestrado, Universidade Federal do Rio de Janeiro, Rio de Janeiro.
Scholl, D.M. \& Ryan, E.B. (1975). Child judgements of sentences varying in grammatical complexity. Journal of Experimental Child Psychology, 20(2), 274-285.

Smith, C.L. \& Targer-Flusberg, H. (1982). Metalinguistic awareness and language development. Journal of Experimental Child Psychology, 34(3), 449-468.

Smith-Lock, K.M. \& Rubin, H. (1993). Phonological and morphological analysis skills in young children. Journal of Child Language, 20(2), 437-454.

Sorace, A. (1985). Metalinguistic knowledge and language use in acquisition - poor environments. Applied Linguistics, 6(3), 239-254.

Tunmer, W.E., Nesdale, A.R. \& Wright, A.D. (1987). Syntactic awareness and reading acquisition. British Journal of Developmental Psychology, 5(1), 25-34.

Wagner, R.K. \& Torgesen, J.K. (1987). The nature of phonological processing and its causal role in the acquisition of reading skills. Psychological Bulletin, 101(2), 192-212.

Yopp, H. (1988). The validity of phonemic awareness tests. Reading Research Quarterly, 23(2), 159-177.

Recebido em 20.08.2003

Primeira decisão editorial em 11.02.2004

Versão final em 01.03.2004

Aceito em 19.03.2004 